\title{
Reacción a "Prevención ambiental de drogas en la Unión Europea. ¿Por qué es tan impopular este tipo de prevención? de Gregor Burkhart"
}

\section{Reaction to the article: Environmental drug prevention in the EU - why is it so unpopular? by Gregor Burkhart}

| FABRIZIO FAGGIANO

n his impressive contribution, Gregor Burkhart (2011) wonders why Europe is still dominated by the concept of pre-

vention based on information on risks and dangers of drugs and of harmful behaviors, administered in schools, peer groups or by mass media campaigns, despite the large amount of evidence of its lack of effectiveness, or, in some cases, its counterintuitive effects, like for many mass media campaigns.

From the data of EMCDDA, the paper suggests that prevention programs based on such ineffective paradigm are still the majority, and that more effective approaches, like those based on Comprehensive social influence (Evans, 1978), are uncommon.

The paper suggests that the use of interventions based on an environmental prevention approach can be an alternative, and gives us a broad overview of this kind of interventions, including a clear definition, and a convincing discussion of their theoretical background and scientific proofs of effectiveness. But, nevertheless, they are still rarer.

Reading the text, I asked myself a question: could these data explain the perceived low impact of prevention programs of substance abuse in Europe?
Avogadro University - Novara, Italy

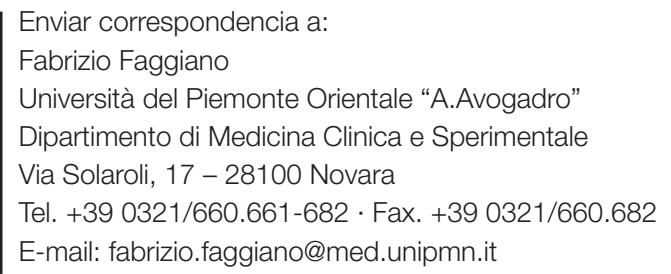

But this is not the only explanation. In my opinion, the answer can be yes. Everybody working on substance use prevention knows that professionals working in the major settings of intervention (school, community, family), once clearly identified the problem, most of the time suggest spontaneously as the main risk factor a lack of information on risks.

Even strong evidence-based interventions, as for example the school-based program Unplugged (Faggiano, 2010), can do little against the pervading social pressure to smoke, (but also to drink or even to use drugs): once the student is exposed to these antidrugs curricula, when he/she leaves the school, has to pass through groups of teachers and students smoking together outside the school, goes home where parents frequently smoke, are exposed to alcohol advertising, to smoking and alcohol scenes in movies, and these are only a small part of the social pressure to use substances.

But this is not the only limit of these programs, because they are usually lacking in coverage: even after a hard effort in dissemination, it is unrealistic to obtain a $100 \%$ of coverage of the target population by an evidence-based intervention. 
This is because it is difficult to involve schools, families, or communities, because interventions are usually complex, and not all professionals are available to dedicate time to carry out them, because there are other priorities, lack of resources, lack of personnel, etc.

The critical issues mentioned before are not intended to discourage the implementation of effective programs at any level of the social system, but to emphasize the additional impact environmental strategies can provide. Changing norms through environmental prevention can increase substantially the impact of prevention at the level of population. School policies and smoke-free homes can, for example, reduce the social pressure around the adolescents, and increase the effect of schools interventions. But the greater contribution of this kind of interventions is coverage: changes in movie rating, excluding films with smoking scenes from general audience, reduces the exposure to smoking scenes to all the adolescents in a nation, and contributes to change the norms on smoking over the whole population (Millett, 2010); bans of advertising of liquors, for example, can reduce the use of alcohol among all the population of adolescents previously exposed to such advertising (Collins, 2007). In principle, any kind of intervention able to change the norms of use of substances, can have an effect in reducing the prevalence of use.

Nevertheless, changing the environment, i.e. "altering the immediate cultural, social, physical and economic environments in which people makes their choices about drug use", in order to reduce the prevalence of substance use, and its effects, is a complex strategy requiring a careful and comprehensive consideration on its ethical aspects. Apart from those raised by Gregor Burkhart, a critical aspect of environmental prevention is the action of changing cultural and social environment in order to promote health. This implies that health should have a higher position in relation to the other values of the society, and that for its aims, it is possible to modify the society. This may not pose ethical problems, as long as the superior role of health as a value in the society has been decided democratically, and is shared by the majority of the population. Otherwise, it can be criticized as a Tyranny of health, as suggested by Fitzpatrick in 2001.

This consideration implies that democracy, and the democratic process of definition of social priorities, plays a major role in building preventive strategies, considering citizens' values and preferences, together of scientific evidence.

\section{REFERENCES}

Burkhart, G. (2011). Environmental drug prevention in the EU. Why is it so unpopular? Adicciones, 23: 87-100.

Collins, R. L., Ellickson, P. L., McCaffrey, D. \& Hambarsoomians, K. (2007). Early adolescent exposure to alcohol advertising and its relationship to underage drinking. Journal Adolescent Health, 40: 527-34.

Evans, R. I., Rozelle, R. M., Mittelmark, M., Hansen, W. B., Bane, A. L. \& Havis, J. (1978). Deterring the onset of smoking in children: Knowledge on immediate psychological effects and coping with peer pressure, media pressure, and parents modelling. Journal of Applied Social Psychology, 8, 126-135.

Faggiano, F., Vigna-Taglianti, F., Burkhart, G, Bohrn, K., Cuomo, L., Gregori, D., et al. (2010). The EU-Dap Study Group. The effectiveness of a school-based substance abuse prevention program: 18-Month follow-up of the EU-Dap cluster randomized controlled trial. Drug Alcohol Dependences, 108, 56-64.

Fitzpatrick, M. (2001). Doctors and the regulation of lifestyle. London. Routledge, Taylor and Francis Group.

Millett, C. \& Glantz, S. (2010). Assigning an "18" rating to movies with tobacco imagery is essential to reduce youth smoking. Thorax, 65 , 377-378. 